\title{
Influence of boulder machine-made sand powder on compressive strength of concrete
}

\author{
Pengtao Wang ${ }^{1, *}$ \\ ${ }^{1}$ China Road and Bridge Co., Beijing 100011, China
}

\begin{abstract}
In order to recycle the boulder powder produced in the process of manufactured sand production and reduce the cost of engineering concrete, this article studied the influence of boulders powder on the compressive strength of concrete. The results show that in the early stage of concrete test, the compressive strength of rock powder concrete is slightly lower than of fly ash and mineral powder concrete. With the development of curing age, the strength of boulders powder concrete developed slower. As the increase of boulders powder content, the compressive strength of different curing age gradually decreased, and it was suggested that the content of boulders powder should be controlled within $20 \%$ of cementitious materials mass. The positive effect of boulders powder fineness on the strength of concrete is limited, so it is suggested to use unprocessed collected boulders powder in the project, which is economical and environmentally friendly. With the adjustment of water-to-binder ratio, boulders powder can be prepared with different strength grades of concrete to meet the needs of engineering; the composite of boulders powder with traditional mineral admixtures, such as fly ash, and especially granulated blast furnace slag powder, can significantly improve the strength of concrete.
\end{abstract}

\section{Introduction}

Phnom Penh-Sihanoukville Expressway (PPSE) is an important golden channel connecting Phnom Penh, the capital of Cambodia, to Sihanouk, the largest seaport in China and an external port. The construction of PPSE is of great significance for promoting the local economic development of Cambodia and implementing the "One Belt One Road" initiative. The starting point of PPSE is at the intersection of National Highway No. 4 and Phnom Penh City Circle Line in Cambodia, and the end point is on the No. 4 road on the edge of Sihanoukville. It is about $8.6 \mathrm{~km}$ away from Sihanoukville Port to the west and about $5.5 \mathrm{~km}$ away from Westport Economy, and it is about $8.5 \mathrm{~km}$ from Sihanoukville Airport. The total length is $187.05 \mathrm{Km}$. The whole line adopts Chinese highway construction standards and specifications. The design speed is $100 \mathrm{Km} / \mathrm{h}$, and the two-way four-lane.

There are a large number of boulders on the hilltops and slopes around the planned route of the project, forming local boulder groups, and piles of boulders can be formed in the river to block the flowing water. The preliminary survey revealed that the irregularly distributed boulders generally have a diameter of 0.50 to $2.00 \mathrm{~m}$, with a maximum diameter of not less than $5 \mathrm{~m}$, and are hard and sub-circular in appearance, whose main minerals are quartz and feldspar. If these boulders are recycled into manufactured sand, it can reduce the cost of sand and gravel procurement and transportation, and reduce the occupation of arable land, which has significant economic and social benefits. Therefore, this article intended to study the influence of manufactured sand prepared by boulders and its gravel powder on the mechanical properties of concrete, aiming to promote the application of boulders manufactured sand and its gravel powder in engineering.

\section{Materials and Methods}

\subsection{Raw Materials}

In this paper, the test concrete is mainly prepared with the following raw materials:

(1) Cement: ordinary Portland cement whose initial setting is $161 \mathrm{~min}$, final setting is $242 \mathrm{~min}, 3 \mathrm{~d}$ and $28 \mathrm{~d}$ compressive strength are $22.3 \mathrm{MPa}$ and $49.2 \mathrm{MPa}$ respectively. The chemical composition is shown in Table 1.

(2) Admixture: polycarboxylate superplasticizer with solid content of $16.2 \%$ and water reducing rate of $18.2 \%$ is selected. The specific surface area (Bertrand method) of fly ash (FA) and granulated blast furnace slag powder (GGBS) are $396 \mathrm{~m}^{2} / \mathrm{kg}$ and $454 \mathrm{~m}^{2} / \mathrm{kg}$, and the density of them are $2.49 \mathrm{~g} / \mathrm{cm}^{3}$ and $2.84 \mathrm{~g} / \mathrm{cm}^{3}$. The chemical composition of FA and GGBS are shown in Table 1.

(3) Fine aggregate: manufactured sand made by boulders is used, which has a fineness modulus of 2.9, a stone powder content of $9.6 \%$, a methylene blue value of 1.1; the fluidity ratio of boulders powder (BP) from the preparation process of manufactured sand is $81 \%$, and the $28 \mathrm{~d}$ activity index is $60 \%$.

\footnotetext{
* Corresponding author: wangpt@crbc.com
} 
(4) Coarse aggregate: $5-20 \mathrm{~mm}$ continuous graded crushed stone is used, and the apparent density of it is $2642 \mathrm{~kg} / \mathrm{m}^{3}$, the bulk density is $1626 \mathrm{~kg} / \mathrm{m}^{3}$, the water absorption is $1.3 \%$ and the crushing value is $6.3 \%$.

Table 1. Chemical composition of cement, FA and GGBS (wt.\%)

\begin{tabular}{|c|c|c|c|c|c|c|c|c|c|}
\hline & $\mathrm{CaO}$ & $\mathrm{Al}_{2} \mathrm{O}_{3}$ & $\mathrm{SiO}_{2}$ & $\mathrm{SO}_{3}$ & $\mathrm{Fe}_{2} \mathrm{O}_{3}$ & $\mathrm{~K}_{2} \mathrm{O}$ & $\mathrm{Na}_{2} \mathrm{O}$ & $\mathrm{MgO}$ & LOI \\
\hline Material type & 72.27 & 3.98 & 18.77 & 3.73 & 0.21 & 0.43 & 0.06 & 0.21 & 0.82 \\
\hline cement & 1.03 & 28.05 & 48.91 & - & - & 2.15 & 2.65 & 0.80 & 3.28 \\
\hline Fly ash (FA) & 32.46 & 15.11 & 36.32 & 1.24 & 0.87 & 0.43 & 0.23 & 8.42 & 1.28 \\
\hline Glast furnace slag powder (GGBS)
\end{tabular}

Table 2 Test mix proportion of contrast admixture type $\left(\mathrm{kg} / \mathrm{m}^{3}\right)$

\begin{tabular}{|c|c|c|c|c|c|c|c|c|c|c|}
\hline \multirow{2}{*}{ No. } & \multirow{2}{*}{$\begin{array}{l}\text { Water - to - } \\
\text { binder ratio } \\
\text { (W/B) }\end{array}$} & \multirow{2}{*}{ Water } & \multirow{2}{*}{ Cement } & \multicolumn{3}{|c|}{ Mineral admixture } & \multirow{2}{*}{$\begin{array}{l}\text { Dosage of } \\
\text { mineral } \\
\text { admixture } \\
(\%)\end{array}$} & \multirow{2}{*}{$\begin{array}{c}\text { Specific surface } \\
\text { area of } \\
\mathrm{BP}\left(\mathrm{m}^{2} / \mathrm{kg}\right)\end{array}$} & \multirow{2}{*}{$\begin{array}{c}\text { Fine } \\
\text { aggregate }\end{array}$} & \multirow{2}{*}{$\begin{array}{c}\text { Coarse } \\
\text { aggregate }\end{array}$} \\
\hline & & & & FA & GGBS & $\mathrm{BP}$ & & & & \\
\hline J1 & 0.45 & 175.5 & 292.5 & 97.5 & - & - & 25 & - & 825 & 1015 \\
\hline $\mathrm{J} 2$ & 0.45 & 175.5 & 292.5 & - & 97.5 & - & 25 & - & 825 & 1015 \\
\hline $\mathrm{J} 3$ & 0.45 & 175.5 & 292.5 & - & - & 97.5 & 25 & 205 & 825 & 1015 \\
\hline $\mathrm{J} 4$ & 0.45 & 175.5 & 370.5 & & & 19.5 & 5 & 205 & 825 & 1015 \\
\hline J5 & 0.45 & 175.5 & 331.5 & & & 58.5 & 15 & 205 & 825 & 1015 \\
\hline $\mathrm{J} 3$ & 0.45 & 175.5 & 292.5 & & & 97.5 & 25 & 205 & 825 & 1015 \\
\hline J6 & 0.45 & 175.5 & 292.5 & & & 97.5 & 25 & 451 & 825 & 1015 \\
\hline J7 & 0.40 & 160 & 300 & & & 97.5 & 205 & 205 & 825 & 1015 \\
\hline J8 & 0.35 & 150 & 322.5 & & & 100 & 30 & 205 & 828 & 1009 \\
\hline J9 & 0.47 & 178.6 & 266 & 38 & - & 76 & $30(10 / 0 / 20)$ & 205 & 828 & 1009 \\
\hline J10 & 0.47 & 178.6 & 266 & - & 38 & 76 & $30(0 / 10 / 20)$ & 205 & 828 & 1009 \\
\hline $\mathrm{J} 11$ & 0.47 & 178.6 & 266 & 22.8 & 22.8 & 68.4 & $30(6 / 6 / 18)$ & 205 & 828 & 1009 \\
\hline
\end{tabular}

\subsection{Testing Methods}

The compressive strength of concrete is tested according to the Chinese standard for test methods of physical and mechanical properties of concrete (GB/T 50081-2019). The size of the test piece is $150 \mathrm{~mm} \times 150 \mathrm{~mm} \times 150 \mathrm{~mm}$. The raw materials of concrete were mixed in the mixer for $90 \mathrm{~s}$, and the test blocks were formed by vibration table. The test blocks were placed in the room with a temperature of $20{ }^{\circ} \mathrm{C}$ and a relative humidity of $60 \%$ for $24 \mathrm{~h}$, and then the molds were removed, and the concrete samples were put into the standard curing room until the testing age.

In order to investigate the effect of BP on the mechanical properties of concrete, this article designed series mix proportion to prepared different concrete samples, just as shown in Table 2. The research variables in this experiment included the mineral admixture types, water-to-binder ratio, content and fineness of BP, and composite effect of mineral admixture.

\section{Results and Analysis}

\subsection{Admixture types}

Fly ash (FA), granulated blast furnace slag powder (GGBS) and boulder powder (BP) were respectively used as mineral admixtures. Under the same dosage of $25 \mathrm{wt} . \%$ (the ratio of binder mass), the concrete performance is tested and compared, and the influence of BP on the compressive strength of concrete is studied. As shown in Table 2, the initial slump of concrete mixture is controlled at $180 \pm 30 \mathrm{~mm}$.

The influence of different mineral admixtures on the compressive strength of concrete was shown in Fig. 1. According to the test results, the compressive strength of $\mathrm{J} 3$ is similar to that of $\mathrm{J} 1$ and $\mathrm{J} 2$ in the early test age, and the compressive strength of concrete contained BP is slightly lower than that of concrete with FA or GGBS. The 3-day compressive strength of $\mathrm{J} 1, \mathrm{~J} 2$ and $\mathrm{J} 3$ were 19.1MPa, 22.1MPa and 20.2MPa, respectively. With the increase of curing age, the developing rate of compressive strength of $\mathrm{J} 3$ is significantly lower than that of J1 and J2. At 56 days, the compressive strength of $\mathrm{J} 3$ is significantly lower. The main reason is that BP is usually inert admixtures, which only plays a filling role in concrete and does not have pozzolanic activity with less contribution of the development of compressive strength. By contrast, the traditional mineral admixtures, FA and GGBS, can not only play a filling effect but also have certain pozzolanic activity, which can react with cement hydration products for secondary hydration, further compact concrete and improve the compressive strength of concrete [1-3]. In general, adding BP to prepare concrete sample will put an adverse effect on compressive strength of concrete, and it can be foreseen that when recycling BP to replace cement mass, the dosage of BP should be limited. 


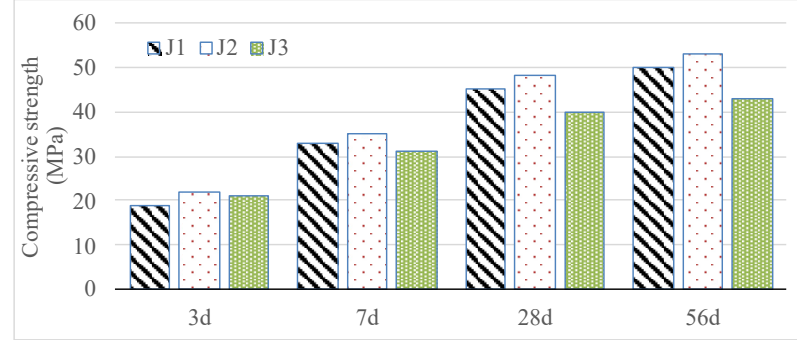

Fig. 1 Influence of admixture types on compressive strength of concrete

\subsection{BP content}

In order to further understand the effect of $\mathrm{BP}$ on compressive strength of concrete, the content of BP was set at $5 \%, 15 \%$ and $25 \%$ of binder mass, respectively, and then the compressive strength of concrete was measured. The mix preparations were shown in Table 2, and the initial slump of concrete mixture is controlled at $180 \pm 30 \mathrm{~mm}$.

The influence of BP content on the compressive strength of concrete was shown in Fig. 2. From the test results, it can be seen that as the increase of BP content, the compressive strength at each curing age gradually decreased. The decrease range of compressive strength when the boulders powder content increased from $5 \%$ to $15 \%$ was smaller than that when the boulders powder content increased from $15 \%$ to $25 \%$. The addition of BP has obvious weakening effect on the compressive strength of concrete. When its content was less than $15 \%$, it exhibited little influence on the compressive strength before 28 days, especially when the curing age was 3 days, and it showed an obvious reduction effect on the compressive strength in later age. When BP content was $25 \%$, the strength development trend of concrete was consistent with that of $15 \%$, but the compressive strength was lower. The main reason was presumed to be that BP is inert powder and does not participate in the process of cement hydration reaction. Therefore, when the amount of BP is large, inert powder particles are more likely to become the initial micro defects in cement hydration products. The greater the amount of boulders powder, the more cement stone defects. It is suggested that the content of BP should be controlled within $20 \%$ of cementitious material mass.

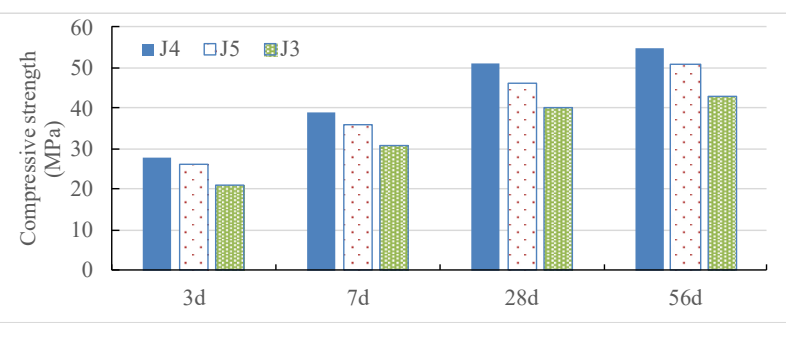

Fig. 2 Effect of boulders powder content on compressive strength of concrete

\subsection{Fineness of BP}

The BP particle collected in the process of manufactured sand production was generally coarse, in order to understand the influence of fineness of BP on the compressive strength of concrete and release the technical value of BP, this article designed two types of concrete sample with different fineness of BP which was obtained through physical grinding with specific surface area of $205 \mathrm{~m} 2 / \mathrm{kg}$ and $451 \mathrm{~m} 2 / \mathrm{kg}$ respectively. The mix proportion was shown in Table 2, and the slump of fresh sample was controlled at $180 \pm 30 \mathrm{~mm}$.

The influence of fineness of BP on the compressive strength of concrete was shown in Fig. 3. The test results showed that the compressive strength of concrete increased with the increase of fineness of boulders powder. Compared with the concrete with specific surface area of $205 \mathrm{~m}^{2} / \mathrm{kg}$, the compressive strength of J6 increased by $9.5 \%, 9.6 \%, 2.5 \%$ and $6.9 \%$ at the age of 3 days, 7 days, 28 days and 56 days, respectively. The finer the powder fineness is, the larger the specific surface area is, the more pores can be filled in the concrete, which makes the concrete structure more compact and improves the compressive strength of concrete. It meant that the finer the fineness of BP, the higher the compressive strength of concrete at each age. However, the improvement of compressive strength was not obvious. In order to achieve a certain fineness, the BP particle need to be ground by corresponding grinding equipment, which not only consumed working time, but also increased the cost. Considering comprehensively, it is not economical to adopt the technical measures of increasing the fineness of $\mathrm{BP}$ to improve the compressive strength of concrete [4-7]. In the actual production and application of concrete, if the stone powder produced by manufactured sand is used, it is recommended to use it directly instead of grinding.

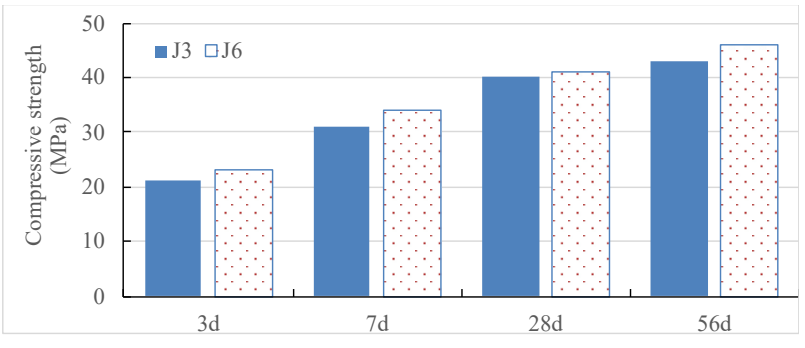

Fig. 3 Effect of fineness of boulders powder on compressive strength of concrete

\subsection{Water-to-binder ratio}

In the process of engineering construction, there are many strength grades of designed concrete. In order to meet the needs of different strength grades of concrete, the water-to-binder ratios of $0.45,0.40$ and 0.35 were used to study the influence of different water-to-binder ratio on the compressive strength of concrete contained BP. Different strength grades of concrete are prepared to broaden the application scope of boulder powder. The mix proportion was listed in Table 2, and the slump of fresh sample was controlled at $180 \pm 30 \mathrm{~mm}$.

The influence of different water-to-binder ratio on the compressive strength of concrete with BP was shown in Fig. 4. The test results showed that the compressive strength of concrete increased with the decrease of 
water-to-binder ratio. When the water-to-binder ratio was 0.45 , the 56 -day compressive strength of concrete was $43.1 \mathrm{MPa}$, reaching the strength requirements of $\mathrm{C} 30$ concrete $\left(f_{c u, 0} \geq f_{c u, k}+1.645 \sigma\right.$, where the $f_{c u, k}$ is the designed strength grade, the $f_{c u, k}$ of C30 concrete is 30, and the $\sigma$ of C30 concrete is 5.0, and the prepared strength $f_{c u, 0}$ should reach $38.23 \mathrm{MPa}$ ), When the water-to-binder ratio was 0.35 , the $56 \mathrm{~d}$ compressive strength of concrete is 63.0MPa, which meets the strength requirements of $\mathrm{C} 50$ concrete $\left(f_{c u, 0} \geq f_{c u, k}+1.645 \sigma\right.$, where the $\sigma$ of C50 concrete is 6.0 , the prepared strength $f_{c u, 0}$ should reach $59.87 \mathrm{MPa}$ ). It could be seen that by adjusting the water-to-binder ratio, different strength grades of concrete required by general engineering can be configured. Therefore, in the construction process, BP can be considered as mineral admixture from the perspective of strength grade.

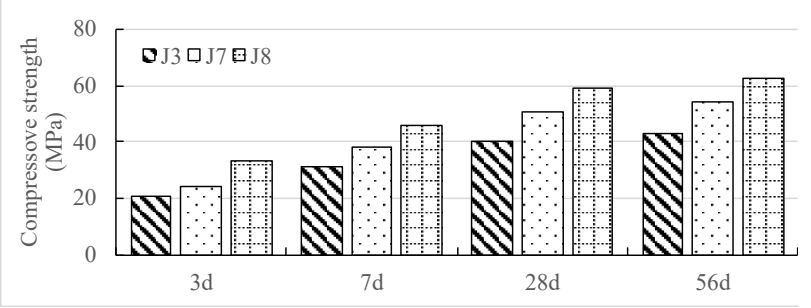

Fig. 4 Effect of water binder ratio on compressive strength of concrete

\subsection{Compound mineral admixture}

In the actual engineering construction process, in addition to the requirements for compressive strength, most projects have certain requirements for concrete durability, so it is necessary to add traditional mineral admixtures, such as FA and GGBS, in the concrete sample during the prepared process. Therefore, the composite addition of BP, FA and GGBS was studied in this section, and the proportion of composite addition and mix proportion were shown in Table 2. The initial slump of concrete mixture was controlled at $180 \pm$ $30 \mathrm{~mm}$.

The influence of composite addition of BP and traditional mineral admixtures on the compressive strength of concrete was shown in Fig. 5. From the testing results, it could be seen that compounding BP and GGBS was more beneficial to enhance the compressive strength than combining BP and FA. At the age of $3 \mathrm{~d}, 7 \mathrm{~d}$, $28 \mathrm{~d}$ and $56 \mathrm{~d}$, the compressive strength of $\mathrm{J} 10$ was $12.0 \%$, $11.1 \%, 8.9 \%$ and $12.0 \%$ higher than that of $\mathrm{J} 9$, respectively. Furthermore, the effect of $6: 2: 2$ ternary composite of BP, mineral powder and fly ash on the compressive strength of concrete was the best, mainly since the composite of traditional mineral admixtures has a certain super superposition effect on particle size gradation and activity. It can be seen from Fig. 5 that the strength growth of the three groups of specimens was consistent throughout the age, the compressive strength growth rate from $3 \mathrm{~d}$ to $7 \mathrm{~d}$ was the largest, followed by $7 \mathrm{~d}$ to $28 \mathrm{~d}$, and the growth rate of 28 to $56 \mathrm{~d}$ was slowest. Fig. 5 also showed that the compressive strength of different mix proportions of concrete at different curing ages was in the order of $\mathrm{J} 9<\mathrm{J} 10<\mathrm{J} 11$. It could be found that the contribution of GGBS on compressive strength of concrete with BP was higher than that of FA, and the ternary composite of BP, GGBS and FA could improve the strength of concrete better than the combination of $\mathrm{BP}$ and a single mineral admixture.

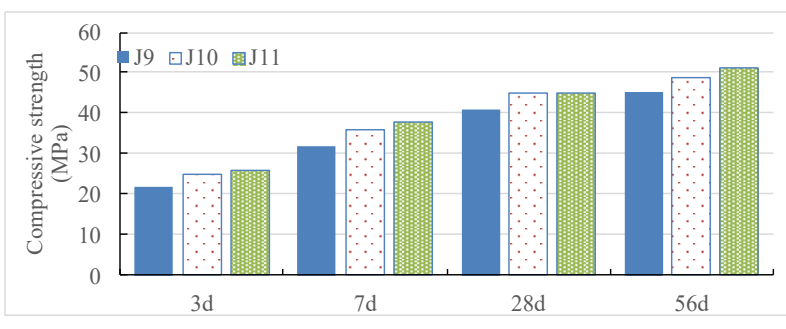

Fig. 5 Effect of different proportion of composite mineral admixture on compressive strength of concrete

\section{Conclusion}

Through the comparison of boulder powder (BP) with fly ash (FA) and granulated blast furnace slag powder (GGBS), the influence of different dosage and fineness, water-to-binder ratio and compounding traditional mineral admixtures on concrete strength was studied, and the conclusions could be drawn as follows:

(1) In the early curing age, the compressive strength of concrete with BP was similar to that with FA or GGBS. The strength of boulder powder concrete ws slightly lower than that of traditional mineral admixture concrete. With the development of curing age, the strength of boulders powder concrete develops slowly.

(2) With the increase of BP content, the compressive strength of each age gradually decreased. It was suggested that the content of BP should be controlled within $20 \%$ of cementitious materials mass; the fineness of BP showed limited effect on the improvement of compressive strength, meaning that raw boulders powder could be used in the project which is economical and environmentally friendly.

(3) Through the adjustment of different water-tobinder ratio, BP could be used to prepare concrete with different strength grades to meet the needs of engineering; and the composite of $\mathrm{BP}$ and traditional mineral admixtures FA or GGBS could significantly improve the strength of concrete, while the positive effect of the ternary composite of BP, GGBS and FA was better.

\section{References}

1. F. Dif, T. H. Douara, R. Zaitri, and M. Mouli, J. Build. Eng. 32, 101835 (2020).

2. S. E. Mohammadyan-Yasouj and A. Ghaderi, Constr. Build. Mater. 252, 119115 (2020).

3. R. Yang, R. Yu, Z. Shui, X. Gao, X. Xiao, D. Fan, Z. Chen, J. Cai, X. Li, and Y. He, J. Clean. Prod. 258, 120673 (2020).

4. R. Choudhary, R. Gupta, R. Nagar, and A. Jain, Constr. Build. Mater. 269, 121282 (2021). 
5. Q. D. Nguyen, A. Castel, T. Kim, and M. S. H. Khan, Cement. Concrete. Res. 139, 106265 (2021).

6. S. Mundra, V. Agrawal, and R. Nagar, J. Build. Eng. 32, 101534 (2020).

7. A. Alnuaim, Y. M. Abbas, and M. Iqbal Khan, Constr. Build. Mater. 274, 121245 (2021). 